\title{
EVALUATION OF ANTICLASTOGENIC POTENTIAL OF CINNAMOMUM CASSIA BARK EXTRACT AGAINST ARSENIC GENOTOXICITY BY USING MICRONUCLEUS ASSAY IN MUS MUSCULUS CAUDAL ERYTHROCYTES
}

\author{
AMBASTA SK*, YADAV AK, SINHA UK \\ Department of Botany, Faculty of Science, Patna University, Patna, Bihar, India. Email: ambasta.2017@gmail.com \\ Received: 11 March 2017, Revised and Accepted: 13 April 2017
}

\section{ABSTRACT}

Objective: The study was aimed to evaluate the anticlastogenic potential of ethanolic extract of Cinnamomum cassia against arsenic-induced genotoxicity.

Methods: In the experiment, 30 animals were taken and divided into five groups and each group contains six animals. Group 1 was control and fed on tap water of Patna city while rest four $(2,3,4,5)$ groups were treated with $4 \mathrm{mg} / \mathrm{kg}$ body weight, per orally sodium arsenite for 8 weeks. Sodium arsenite pre-treated Groups 4 and 5 were followed by dose of $100 \mathrm{mg} / \mathrm{kg}$ body weight of $5 \%$ ethanolic solution of test plant bark extract for next 8 weeks (total duration of dosing 16 weeks). Caudal blood collected from each mouse by minor nick without their sacrifice and smeared blood was stained by double staining. Approximately, 2000 cells were scored by light microscopy to determine micronucleus (MN) frequency. The percentage of MN frequency was expressed in the terms of mean and standard deviation.

Results: High index of MN frequency was observed in the Groups 2 and 3 while its frequency drastically reduced in Groups 4 and 5 . The mean number of MN scored per 2000 cell were found to be 4.5, 23.5, 18.8, 10.5, and 9.66 in animal Groups 1, 2, 3, 4, 5,respectively.

Conclusion: C. cassia may be effective drug in the area of preventive cancer or other kinds of diseases which lead to damage of genetic materials.

Keywords: Clastogen, Sodium arsenite, Spindle apparatus, Genotoxicity, Mitotic delay.

(c) 2017 The Authors. Published by Innovare Academic Sciences Pvt Ltd. This is an open access article under the CC BY license (http://creativecommons. org/licenses/by/4. 0/) DOI: http://dx.doi.org/10.22159/ajpcr.2017.v10i7.18417

\section{INTRODUCTION}

Micronucleus (MN) formation is a hallmark of genotoxicity and it is chromatin containing bodies that represent fragments of chromosome or may be whole chromosome that was not incorporated into the daughter cell nucleus at cell division [1]. Induction of MN can result from clastogens or aneugens (agent that induces chromosomal loss mainly through interference with spindle apparatus). The MN is an excellent biomarker for genotoxicity screening because it can detect chromosome breakage or ill functions of mitotic spindle caused by aneugenic mechanism [2]. The major mechanism responsible for micronuclei induction is double stranded DNA breaks and such assay is rapid, easy and sensitive method for detection of mutagenicity [3]. It may detect clastogens or aneugens besides mitotic delay, apoptosis and chromosomal loss or non-disjunction of chromosomes. The MN index in rodents or human cells is one of the excellent cytogenetic tests used in the assessment of genetic toxicity in-vivo or ex-vivo [4]. MN test not only allows the detection of genotoxicity but it also discriminate clastogens from an aneugens [5]. In the genotoxicological studies, the formation of micronuclei in bone marrow and caudal blood erythrocytes is an established protocol for in-vivo cytogenetic assay [6]. The in-vivo MN assay in rodents has been widely accepted for genotoxic studies of chemical compounds and anticlastogenic potenza of new chemicals in pharmaceuticals. Those cells are considered micronucleated in which micronuclei are defined chromatin corpuscles with a diameter $\leq 1 / 3$ of main cell nucleus and stained equally or lighter than the parent nucleus [7]. MN test using blood erythrocytes, the blood can be collected for extended period and chronic and sub-chronic exposure of clastogens can be evaluated for the same animal in the given conditions [8].

Human including several animals is mainly exposed to arsenic via drinking water or due to other anthropogenic activities [9]. Arsenicals are considered as potent genotoxic and may be proved as carcinogenic based on its physical and chemical forms, concentration and duration of exposure [10]. Arsenic-induced mutagenesis causes induction of DNA damage and wide varieties of genetic alterations which can range from single gene mutation to visible chromosomal mutations. Arsenicals mainly concerned with generation of reactive oxygen species (ROS) during its biotransformation inside the living cells, generation of ROS causes DNA strand breaks, and chromosomal aberrations [11]. Clastogenic effect of arsenicals is mediated by inhibition of DNA repair mechanism [12].

Essential oil from aromatic medicinal plants possesses biologically active compounds which are used in the treatment of disorders caused due to oxidative stress [13]. Lots of medicinal herbs and plants are great reservoir of biologically active compounds which may affect the genetic health and general health by maintaining the concentration level between consumption of mutagenic and antimutagenic chemicals [14]. Many herbs houses phenolic and flavonoids as a bioactive component which imparts antioxidant potency and it is proven from various researches that intake of polyphenolic compound lowers down the oxidative stress which might be a cause of cancer [15]. The active chemicals of Cinnamomum cassia show the antineoplastic and antioxidative properties [16]. Phenolic compounds and their derivatives isolated from herbs or medicinal tree shows the antioxidative, anti-inflammatory, antimutagenic, anticarcinogenic, and antitumor properties which impart their potent chemopreventive role. It is evident that ethanolic extract of medicinal plants may be useful in preventing deleterious effect of oxidative stress caused by arsenicals [17].

In this study, antigenotoxic or antimutagenic effects of $C$. cassia bark extracts were investigated against arsenic genotoxicity in Swiss albino mice using MN test in caudal blood sample. 


\section{METHODS}

\section{Experimental animal}

Healthy albino Swiss mice was housed under good hygienic condition and allowed to acclimatize for 10 days under controlled condition of illumination (a $12 \mathrm{hrs}$ light: Dark cycle) and temperature $22-25^{\circ} \mathrm{C}$. The animals were maintained on standard pellet diet and provided with husk bedding throughout the experiment. The study was approved by the Institutional Animal Ethics Committee.

\section{Chemicals}

Sodium arsenite (Sigma, chemical abstracts service (CAS): 7784-46-5), ethylenediamine tetraacetic acid (EDTA) (Sigma, CAS 6381-92-6), and glacial acetic acid (Merck, CAS: 64-19-7) are purchased from local supplier (Bihar Scientific Chemicals, Ashok Raj Path, Patna, India). All the other chemicals used for the experiment were of analytical grade.

\section{Extract preparation of test plant material}

The bark of test plant was purchased from reputed shop of Phulwari sharif, Patna, Bihar. The plant material was identified and authenticated by Department of Botany, Patna University, Patna. The bark (100 g) of C. cassia was washed with distilled water properly and allowed to dry at $40^{\circ} \mathrm{C}$ for 10 days in hot air oven. The dried plant material was milled into fine powder and dissolved in $90 \%$ ethanol then suspension was placed on horizontal shaker for $24 \mathrm{hrs}$. The mixture was subjected to separation of extract by vacuum rotavator (Buchi, R-3) at bath temperature $55^{\circ} \mathrm{C}$, rotation $6 \mathrm{rpm}$ and pressure was maintained at 310 millibar. The extract was evaporated till their dryness and obtained crude product was stored at $4^{\circ} \mathrm{C}$ for future use.

\section{Herbal dose preparation from test plant extract}

Fresh herbal dose was prepared every day before their administration to animals. Dose was prepared by dilution of dried crude extract of C. cassia bark in $5 \%$ ethanol which was vortexed for their mixing for 2-3 minutes. The mixture was then filtered by Whatman filter paper 01 (Cat No: 1001110) of pore size $110 \mathrm{~nm}$. The routes of administration of herbal dose and arsenicals both were oral to the experimental animal.

\section{Experimental design}

Double staining procedure was used in this study, in such staining method Giemsa stain was followed by Harris hematoxylin staining. The mice were divided into five groups comprising six animals in each group. Each cage was numerically marked as 1, 2, 3, 4, and 5 for group categorization. Animals of Group 1 was fed with clean tap water supply of Patna city, Bihar (India) behaved as control while animals of Groups 2, 3, 4, 5 were received sodium arsenite at the rate of $4 \mathrm{mg} / \mathrm{kg}$ body weight, per orally for 8 weeks. After completion of 8 weeks Groups 4 and 5 (sodium arsenite pretreated group) were received $100 \mathrm{mg} / \mathrm{kg}$ body weight, per orally C. cassia bark extract for next 8 weeks (total duration of dosing was 16 weeks). The doses were administered to every individual of each group with an accordance of their body weight, daily once. Caudal blood sample was collected from each animal by minor nicking on their tail tip for MN estimation. About 5-7 $\mu$ l of blood collected from animal and immediately mixed with $3 \%$ EDTA to prevent their clotting. Blood was smeared on surface sterilized glass slide (Blue star industries) of dimension $75 \mathrm{~mm} \times 25 \mathrm{~mm} \times 1.35 \mathrm{~mm}$ with variation in thickness $\pm 0.1 \mathrm{~mm}$. The slides were air dried at room temperature then blood erythrocytes were fixed in $100 \%$ cold methanol for one minute then slides were incubated for $8 \mathrm{hrs}$ at $42^{\circ} \mathrm{C}$. The fixed erythrocytes were stained with Harris hematoxylin mixed with $3.5 \%$ glacial acetic acid for 10 minutes. Glacial acetic acid improves the specificity of chromatin material. Slides were then stained with 1/9 diluted Giemsa stain for 10 minutes which was followed by washing process by distilled water to remove excess of stain. Double staining procedure causes enhanced clarity of $\mathrm{MN}$ and scoring time. Two slides were made for each sample and number of micronuclei scored by two different observers to minimize error. Around 2000 cells were observed per slide to score micronuclei with light microscope (Olympus) under $10 \times ; 100 \times$ magnification. During scoring of each slide, five fields were focused and each field contained approx 350-450 erythrocytes. Frequency of MN was used to evaluate the clastogenic effects of arsenicals as well as anticlastogenic potential of test plant. The percentage MN frequency was expressed in terms of mean, standard deviation (SD) and variance.

\section{RESULTS}

\section{Mean body weight (g) of treated mice}

The mean body weight of mice (Fig. 1) revealed that animals of Groups 2 and 3 (sodium arsenite treated) showed decreasing tendency due to arsenical treatment while $C$. cassia administered Groups 4 and 5 reflects rise in the mean weight of animals. The Group 1 (control) depicts uniformly increasing in weight.

\section{Mean value of MN/2000 cells scored}

Those cells are considered micronucleated in which micronuclei are defined chromatin corpuscles with a diameter $\leq 1 / 3$ of main cell nucleus and stained equally or lighter than the parent nucleus. The mean number of MN is very high in Groups 2 and 3, but there is drastically decline in its number in Groups 4 and 5 (Fig. 2). The average number of MN scored per 2000 cell were found to be 4.5, 23.5, 18.8, 10.5, and 9.66 in Groups 1, 2, 3, 4, 5, respectively.

\section{Determination of percentage frequency of MN by mean and SD}

Percentage frequencies of MN were used to assess genotoxicity caused by arsenicals as well as evaluation of anticlastogenic potential of test plant. It is calculated using simple formula: $\% \mathrm{MN}$ frequency $=($ Number of $\mathrm{MN} /$ Number of total cells scored) $\times 100$. Percentage frequency of micronuclei was expressed in the terms of mean; SD and variance which were shown in Table 1 for different treated groups.

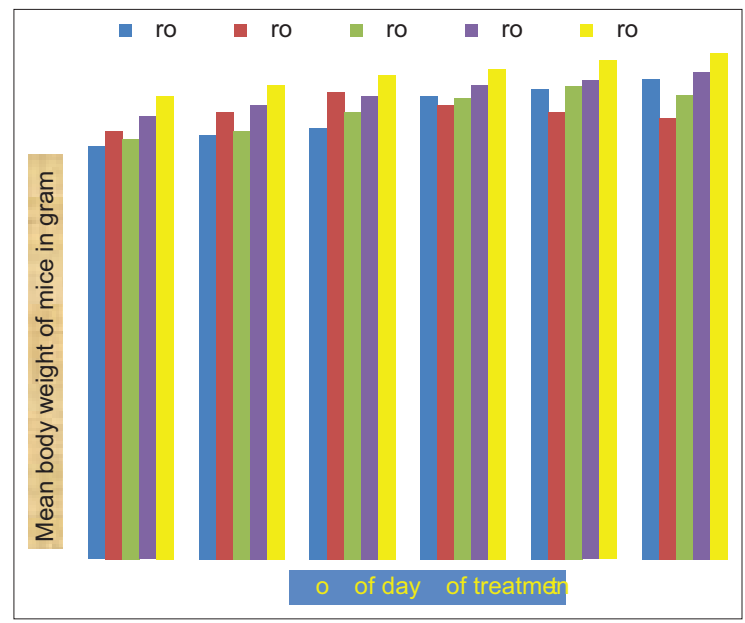

Fig. 1: Mean body weight of treated mice

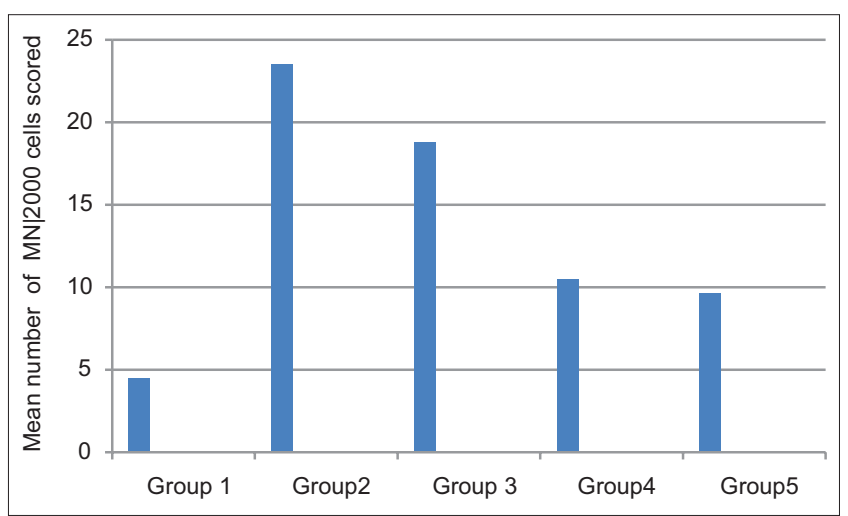

Fig. 2: Mean value of micronucleus in different experimental groups 
Table 1: Mean and SD of MN frequency in mice peripheral caudal blood

\begin{tabular}{|c|c|c|c|c|}
\hline Group & Treatment & Dose (mg/kg/body weight) & $\%$ Frequency of $M N$ mean \pm SD & Variance \\
\hline 1 & Tap water & 0 & $0.225 \pm 0.1129$ & 0.0127 \\
\hline 2 & Sodium arsenite & 4 & $1.175 \pm 0.4298$ & 0.1847 \\
\hline 3 & & & $0.941 \pm 0.1881$ & 0.0354 \\
\hline 4 & C. cassia bark extract & 100 & $0.525 \pm 0.1809$ & 0.0327 \\
\hline 5 & & & $0.483 \pm 0.1807$ & 0.0326 \\
\hline
\end{tabular}

SD: Standard deviation, C. cassia: Cinnamomum cassia, MN: Micronucleus
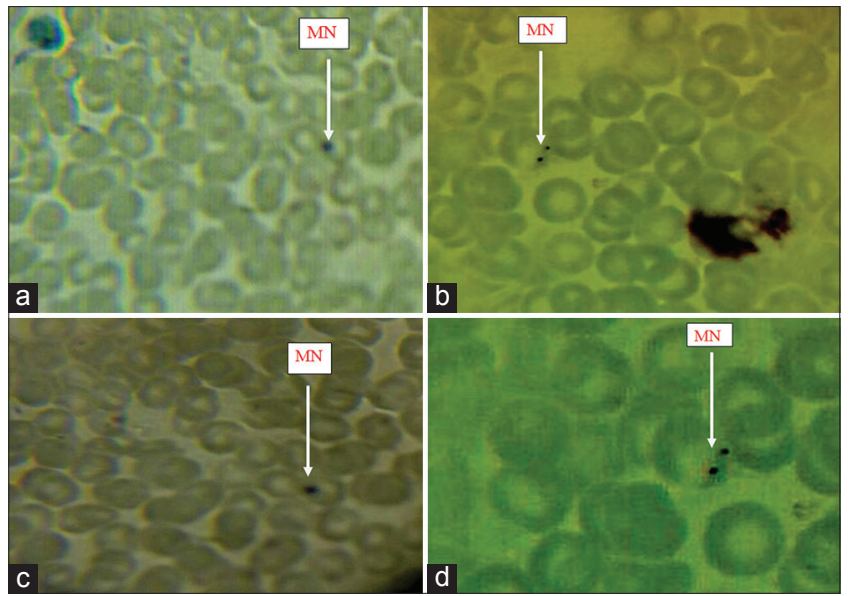

Fig. 3: Microphotograph (a-d) showing micronuclei in caudal erythrocyte at magnification $(10 \times 100)$ under oil immersion

\section{DISCUSSION}

Arsenicals are reported as notorious clastogen which causes formation of micronuclei (Fig. 3). Contrary to this C. cassia shows anticlastogenic potential against arsenical genotoxicity to a great extent. This was confirmed by present investigation and analysis of data which depicts that frequency of micronuclei was drastically decreased in those animal groups those were treated with test plant bark extract. This was probably happens due to repairing action of $C$. cassia for the chromatin material. The mean number of $\mathrm{MN}$ and their percentage frequency (mean \pm SD) were falls down in Groups 4 and 5 in comparison to Groups 2 and 3. Groups 2 and 3 received sodium arsenite alone while Groups 4 and 5 were received an ethanolic extract of test plant material after exposure of sodium arsenite orally. Thus, Cinnamomum cassia may have a good anticlastogenic effect on arsenic-induced genotoxicity.

\section{CONCLUSION}

Arsenicals significantly induce micronuclei formation through clastogenic or aneugenic mechanism which may also directly causes DNA strand breakdown due to generation of ROS. Since test plant bark ethanolic extract may have antimutagenic or anticlastogenic property so it is noteworthy in the preventive aspects of diet and water in chemical carcinogenesis due to arsenic and other types of genetic damages. Hence, the herbal extracts may be used as effective drug in the area of preventive cancer or other kinds of diseases which lead to damage of genetic materials. The findings of this study have revealed that $C$. cassia may be used as preventive herbal drug against chemical toxicity.

\section{ACKNOWLEDGMENT}

This study was financially supported by Ministry of Science and Technology (Government of India) under project named as DBT-PU-IPLS,
Sanction No: BT/PR4577/INF/22/149/2012. We were also thankful to Mahavir Cancer Research Institute, Patna, India, for technical support.

\section{REFERENCES}

1. Kousar S, Javed M. Studies on induction of nuclear abnormalities in peripheral blood erythrocytes on fish exposed to copper. Turk J Fish Aquat Sci 2015;15:879-86.

2. AL-Amery AM. Evaluate micronuclei in the peripheral blood lymphocyte of sarcocystosis infected ewes. Int J Res Dev Pharm Life Sci 2016;5:1929-33.

3. Endoh D, Hashimoto N, Sato F, Kuwabara M. Micronucleus test in mice fed on an irradiated diet. Jpn J Vet Res 1989;37(2):41-7.

4. Zaizuhana S, Puteri J Noor MB, Noral'ashikin Y, Muhammad H, Rohana $\mathrm{AB}$, Zakiah I. The in vivo rodent micronucleus assay of Kacip fatimah (Labisia pumila) extract. Trop Biomed 2006;23(2):214-9.

5. Zelazna K, Rudnicka K, Tejs S. In vitro micronucleus test assessment of polycyclic aromatic compound. Environ Biol 2011;7:70-80.

6. Filho AA, Fernandes HM, Meireles DR, Batista TM, Lima EO, Pessoa HL. Assesssment of genotoxic effects of flavonoid 5, 7, 4-Trimethoxyflavone. Int J Pharmacogn Phytochem Res 2015;7:540-42.

7. Abrevaya XC, Carballo MA, Mudry MD. The bone marrow micronucleus test and metronidazole genotoxicity in different strains of mice (Mus musculus). Genet Mol Biol 2007;30:1139-43.

8. Xhou X, Loarca GF, Arreola GG, Lecona SU. Mouse - Erythrocyte micronucleus (Mus-EMN) assay on the clastogenicity of industrial wastewater. Rev Int Contam Ambient 1995;11:95-8.

9. Klein CB, Leszczynska J, Hickey C, Rossman TG. Further evidence against a direct genotoxic mode of action for arsenic-induced cancer. Toxicol Appl Pharmacol 2007;222(3):289-97.

10. Ahmed MK, Habibullah-Al-Mamun M, Hossain MA, Arif M, Parvin E, Akter MS, et al. Assessing the genotoxic potentials of arsenic in tilapia (Oreochromis mossambicus) using alkaline comet assay and micronucleus test. Chemosphere 2011;84(1):143-9.

11. Unni B, Das S, Bhattacharjee M, Wann SB, Rao PG. Toxicological effects of arsenic exposure in a freshwater teleost fish, Channa punctatus. Afr J Biotechnol 2012;11:4447-57.

12. Szymanska-Chabowska A, Antonowicz-Juchniewicz J, Andrzejak R. Some aspects of arsenic toxicity and carcinogenicity in living organism with special regard to its influence on cardiovascular system, blood and bone marrow. Int J Occup Med Environ Health 2002;15(2):101-16.

13. Arunodaya HS, Krishna V, Shashikumar R, Kumar KG. Antibacterial and antioxidant activities of stem bark essential oil constituents of Litsea glutinosa C.B. ROB. Int J Pharm Pharm Sci 2016;8:258-64.

14. Sharma V, Agrawal RC. Evaluation of anticlastogenic effects of Glycyrrhiza glabra root extract against cyclophosphamide induced chromosomal aberration in Swiss albino mice. J Appl Pharm Sci 2015;5(6):127-32.

15. Fatima Z, Abderrahmane B, Seddik K, Lekhmici A. Antioxidant activity assessment of Tamus communis L. Roots. Int J Pharm Pharm Sci 2016;8:64-71.

16. Lamfon NA. Cinnamomum aqueous extract ameliorates Deltamethrininduced hepatotoxicity in the albino rats. Res J Pharm Biol Chem Sci 2014;5:898-905.

17. Aqil F, Ahmed I, Mehmood Z. Antioxidant and free radical scavenging properties of twelve traditionally used Indian medicinal plants. Turk J Biol 2006;30:177-83. 